\title{
Instability of Dielectric Liquid Surface under the Action of HV Corona Discharge Pulses
}

\author{
Alexander Korolev \\ Russian State Scientific Center for Robotics and Technical Cybernetics (RSSC RTC), St. Petersburg, Russia \\ Email: a.korolev@rtc.ru
}

How to cite this paper: Korolev, A. (2018) Instability of Dielectric Liquid Surface under the Action of HV Corona Discharge Pulses. Open Access Library Journal, 5: e4269.

https://doi.org/10.4236/oalib.1104269

Received: December 19, 2017

Accepted: January 19, 2018

Published: January 22, 2018

Copyright $\odot 2018$ by authors and Open Access Library Inc.

This work is licensed under the Creative Commons Attribution International License (CC BY 4.0).

http://creativecommons.org/licenses/by/4.0/

\begin{abstract}
Instability of liquid dielectrics surface, being developing after the action of an alternating current corona discharge pulse, has been experimentally investigated. Voltage amplitude on the corona electrode reaches $70 \mathrm{kV}$, frequency is $17 \mathrm{MHz}$, and pulse duration is $0.5-1 \mu \mathrm{s}$. This is similar to rose-window instability at electrode height above the liquid surface $>5-10 \mathrm{~mm}$. At lesser heights, development of a singular crater is observed with turbulization of its walls surrounded by radially divergent wrinkles on the surface. In this case, instability shape is similar to an oculus. Maximum effect is demonstrated by oils with high specific electric resistance.
\end{abstract}

\section{Subject Areas}

Fluid Mechanics, Plasma

\section{Keywords}

Dielectric Liquids, Crater Instability, Rose-Window, Oculus

\section{Introduction}

The researches of the corona discharge effect on dielectric liquids have been conducted since the middle of the 20th century [1]. Electrohydrodynamic instabilities formed on the surface of dielectric liquids are caused by extrusion of the latter from the discharge region. Two physical mechanisms of such an extrusion can be distinguished: the discharge ionic wind pressure [2] [3] and the electrostatic repulsion on the charged surface [4]-[14]. The ionic wind pressure is detected in dielectrics with a relatively high electrical conductivity, which ensures passage of a sufficiently high current of the barrier discharge through them. The current lowers liquid dielectric surface electric potential, allowing the ions to 
reach it and transfer their momentum. In the latter case, presence of a barrier discharge is not required. Ions or electrons from the corona discharge, falling on the surface of a liquid dielectric with a low electrical conductivity, charge it to a high potential. The sign of induced potential coincides with that of the corona-producing electrode, in consequence of which, initial pulse of electrostatic repulsion force emerges. Tensile stresses increase with further accumulation of the surface charge.

Suchlike electrostatic repulsion was being observed for thin oil films upon the availability of a low barrier discharge [4] [5] [6] [7]. Spreading of silicone oil drops on a steel substrate is described in the papers [4] [5]. A hydraulic jump arising on the surface of a diesel oil film under an electrode and the accompanying radial compression waves have been investigated in the paper [6]. Fragmentation of a stearine film into drops is observed in the paper [7]. While a corona discharge is being applied to a liquid dielectric thick layer, a surface instability of rose-window type appears [8]-[14]. Such instability is accompanied by a convective instability in the liquid volume [8]. If the instability is secondary, that is, it occurs against the background of the previous one, the pattern of irregularities on the surface will be more complicated [9]. The geometric forms of rose-window instabilities have been investigated in the paper [11]. The influence of the voltage on corona-producing electrode and the oil temperature on the diameter of instability being observed in the form of a single funnel has been investigated in the paper [12]. Exposure of a quartz oil container bottom is observed at continuous movement of negative $26 \mathrm{kV}$ pulses with a frequency of $5 \mathrm{kHz}$. In this case, the instability edges begin to fall into splashes. The instability on the surface of dielectric liquid thick layers under the influence of alternating voltage single pulses on the corona-producing electrode with an amplitude of up to 70 $\mathrm{kV}$ and a frequency of about $17 \mathrm{MHz}$ is investigated in this paper. The observed Instabilities have specific shape similar to an oculus. Activities of the liquids with different resistivity and viscosity are compared.

\section{Experiment Description}

A schematic layout of the experimental setup is shown in Figure 1. The source of high voltage pulses ("Laska-super" Taser) 1 is located on the stand. DC power supply is used for the source instead of a battery. Voltage is applied to the corona-producing electrode 2 as well as to the cutting-out electrodes. The corona-producing electrode is a steel needle with the diameter of $1 \mathrm{~mm}$ and a pointed tip. The needle is located on the axis of the Petri dish with a liquid dielectric 3. Photographing of an instability region is fulfilled via the camera 4; a flashlight 5 is used for backlighting. The height of the needle tip above the liquid surface is adjusted with a ruler on a tripod 6. Profile of the tip is similar to parabolic, see Figure 2.

The breakdown voltage of the source discharge gap is $70 \mathrm{kV}$ on the cutting-out electrodes according to the source specification. These electrodes have 


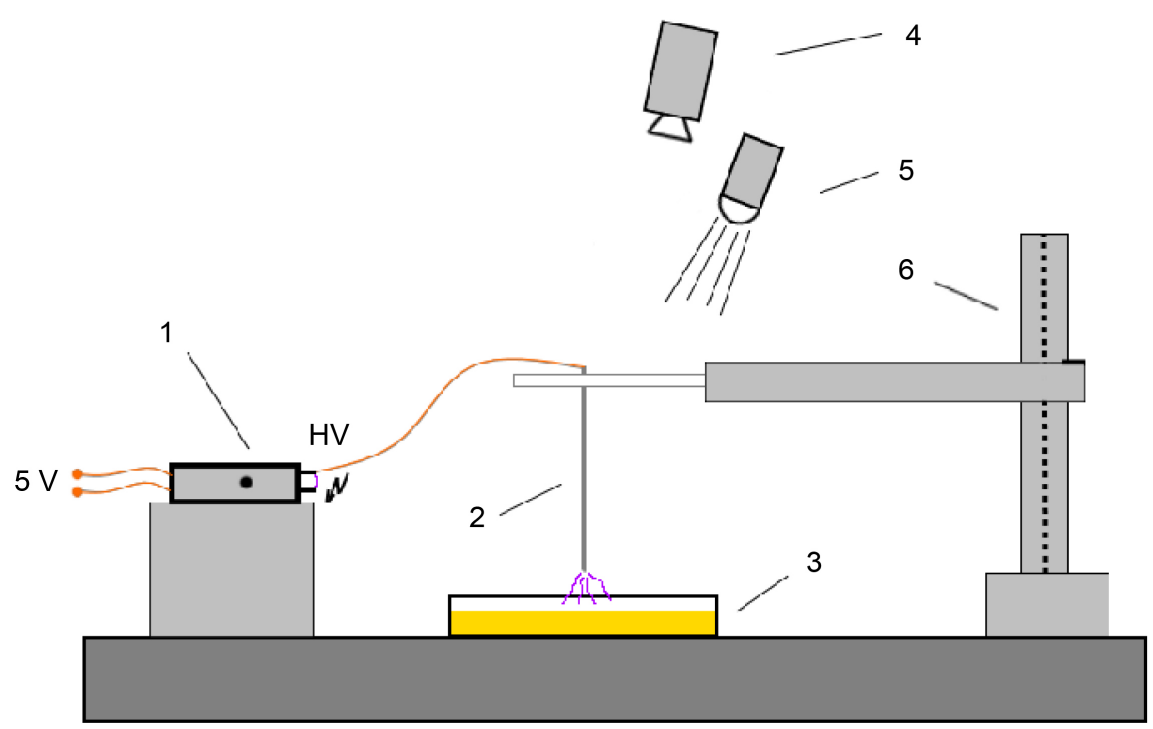

Figure 1, Plant layout.

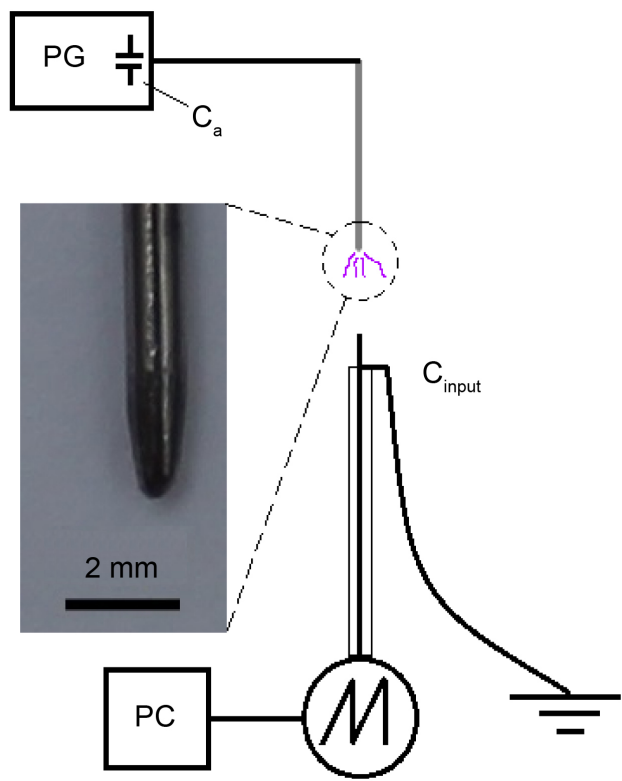

Figure 2. Scheme of the installation for electric field measurements near the corona-producing electrode.

conical tips with a distance between them of $20 \mathrm{~mm}$. However, the voltage on the needle can be lower due to the electric capacity. The voltage drop depends on the ratio of needle with supply wire capacity charging rate to the rate of rise of a spark discharge current between the cutting-out electrodes. A digital USB-oscilloscope with standard probe in the grounded shielding connected to it was used to record the magnitude and shape of electric field pulses from the corona-producing electrode, see Figure 2. The probe was fixed on a tripod at a distance of $50 \mathrm{~mm}$ between the probe and the needle tip. Four images of pulses obtained from recorded signal are shown in Figure 3(a). Pulses (a) are produced 


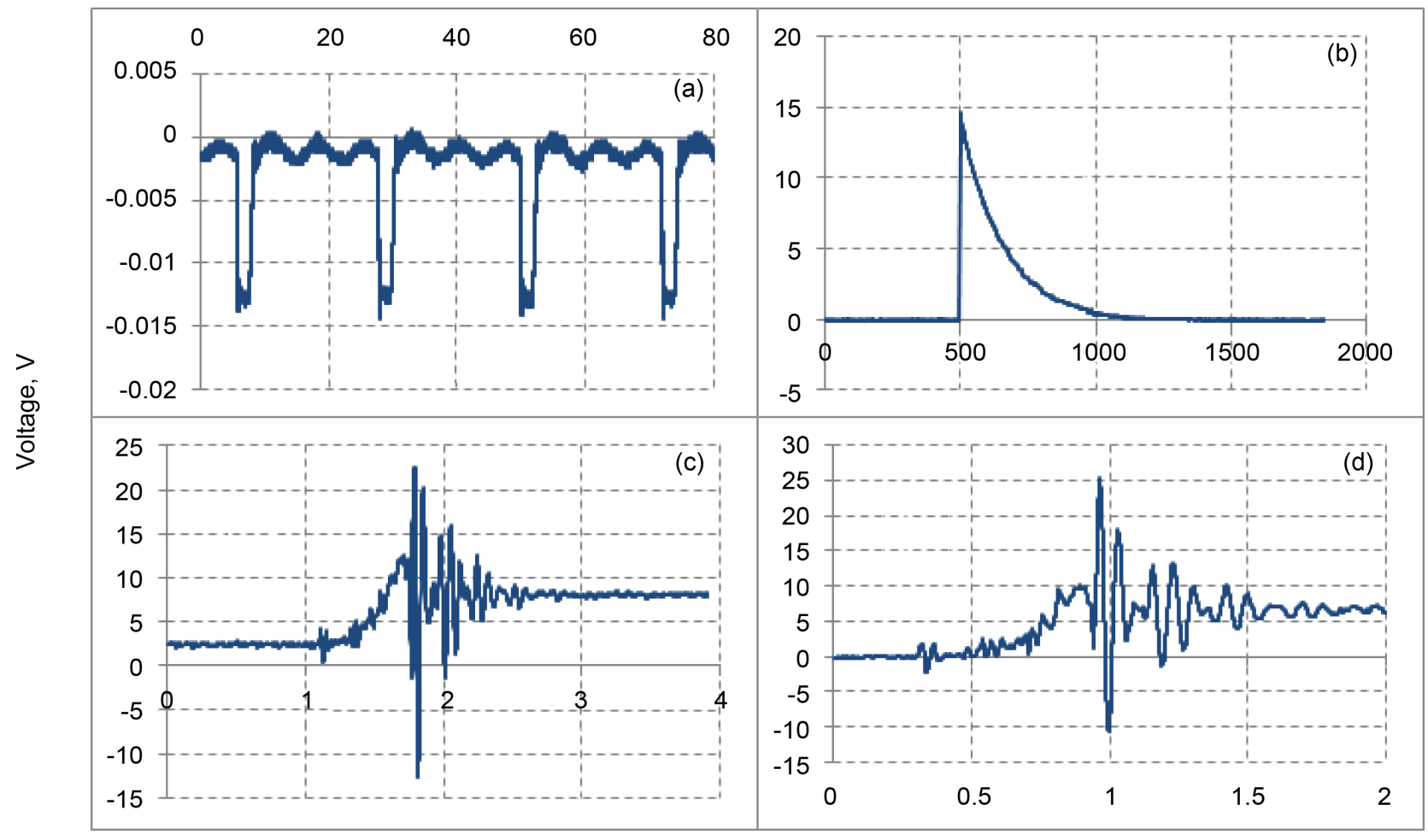

Time, $\mu \mathrm{s}$

Figure 3. Images of the electric pulses obtained with the oscilloscope: (a) small PG charging pulses; (b) discharge pulse of the probe capacitance; (c), (d) typical HF pulses proportional to electric field intensity near the corona-producing electrode.

by the blocking oscillator inside the source. The pulse burst of up to a $200 \mathrm{~ms}$ duration charges output accumulative capacitors $\mathrm{C}_{\mathrm{a}}$. High electric field appears near the corona-producing electrode after breakdown of the discharge gap. The field charges input capacitance of the probe $\mathrm{C}_{\text {input }}$. Long discharge process of this capacitance through the input chain one can see in Figure 3(b). Two typical views of HF pulses proportional to the electric field are presented in Figure 3(c) and Figure $3(\mathrm{~d})$. They can be used to estimate the duration $(0.5-1 \mu \mathrm{s})$, frequency (about $17 \mathrm{MHz}$ ), and the range in the electrode electric field intensity amplitude - up to 2 times in a series of 10 sequential recordings (as well as for the pulses (b)). Such a spread can be caused by instability of spark discharge current rise rate. Corona discharge near the electrode tip is a streamer one [15] [16] and consists of thin luminous channels (streamers) of about $20 \mathrm{~mm}$ long being visible in the dark.

The filming was being fulfilled via a digital camera in video mode. Multiple source switchings were being carried out during the video recordings. Resolution of the video frames has a HD-quality, shooting speed is 50 frames/s. Sensitivity, shutter speed and aperture were adjusted automatically depending on the external lighting intensity. The center-weighted average metering mode was used. A lamp with white LEDs and a sheet of white paper under the cup generating a diffused light were being used to visualize irregularities on the surface of 
the liquids. To study an intensity and lifetime of the instabilities, a number of dielectric liquids with various specific electric conductivity and viscosity was being used.

\section{Results and Discussion}

\subsection{Characteristic Type of Instability}

The series of frames showing the development of instability on the surface of sunflower oil are shown in Figure 4(a) and Figure 4(b). The oil layer thickness

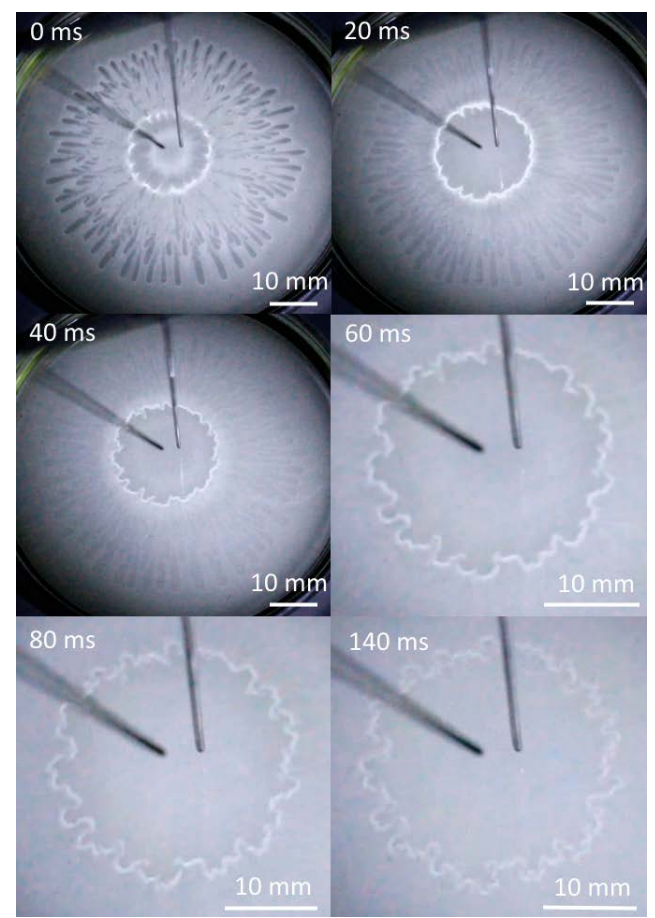

(a)

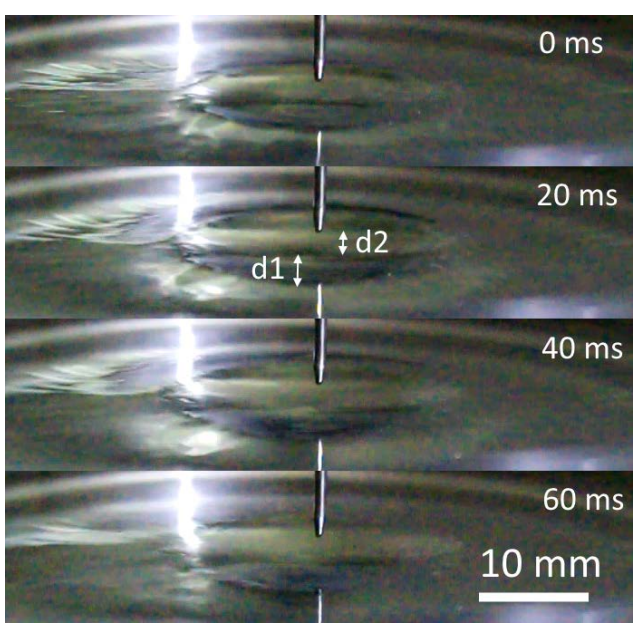

(b)

Figure 4. (a)-(b) The development of instability on the surface of sunflower oil. Electrode position height above the surface is $2 \mathrm{~mm}$, and the pulse voltage is up to about $70 \mathrm{kV}$. 
is $8 \mathrm{~mm}$, the distance from the electrode tip to the surface is $2 \mathrm{~mm}$. At the first moment of time, a small funnel with divergent radial wrinkles appears across the entire area of instability. Then, the funnel expands; its walls are turbulizing and taking a tortuous form. At the last stage, the walls slowly spread out with tortuosity increase. The funnel looks like to be shifted regarding the electrode tip in Figure 4(a). This is due to backlight refraction in the liquid and depends on the flashlight position. Small parallax effect plays the role also. Parallax becomes well-observed at higher distances between the tip and the surface. Small attracting electro-hydrodynamic forces were identified after the instabilities disappearance by small meniscus formation under the electrode. The meniscus had being connected with the electrode tip at the distances of $<1 \mathrm{~mm}$ showing polarization nature of these forces. They are weak in comparison with the repulsive forces, especially at the higher distances.

A hydraulic jump has the form of tortuous bright border of the funnel in Figure 4(a) and of smooth surface bore in Figure 4(b). The jump propagation average velocity in the radial direction calculated using the first two frames in Figure 4 (a) is about $75 \mathrm{~mm} / \mathrm{s}$. Graphical approximation of the border curves by mean circles was made to calculate it. The velocity was obtained via dividing of the circles diameter difference by the time interval of $20 \mathrm{~ms}$. The funnel depth $\mathrm{d}_{1}$ and the jump height above the surface $d_{2}$ may be estimated from Figure $4(b) . d_{1}$ is about $3 \mathrm{~mm}$ and $\mathrm{d}_{2} \sim 2 \mathrm{~mm}$. The hydrodynamic numbers should be calculated to characterize this type of instability and to compare with other ones. The funnel diameter is chosen as the characteristic length scale in them. Thus the Bond number is about 127, the Weber number $\sim 3,6$ and the Reynolds number $\sim 26$. A similar situation of the instability development was being observed in the transformer oil under the same conditions. A small difference is being observed at the relaxation stage. The tortuosities are better expressed and last for a longer time (See Figure 5); vortices appear in some places. This can be explained by the higher viscosity of the transformer oil. Relative low Reynolds number tells about the main reason of the observed turbulization is not a viscous friction but a break of the funnel walls due to tensile stress.

The funnel development of the instability being observed is similar in the first approximation to that of a mechanical impact on a liquid surface, for example, while a drop is falling [17]. The formation of wrinkles is similar to the case of a

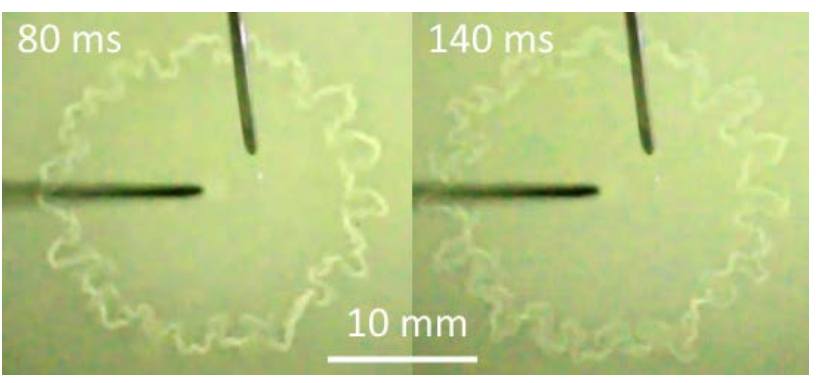

Figure 5. Turbulization of the funnel walls on the surface of transformer oil. The pulse voltage is up to about $70 \mathrm{kV}$. 
mechanical impact on a strained membrane. In this case, the stresses resulting in the membrane are caused by radial tension forces. The wrinkles on the charged surface of a liquid dielectric can be caused by electrostatic repulsion forces. At this moment, the formation of regular wrinkles on the surface of liquid dielectrics under the action of dielectrophoresis forces is described [18] [19]. The wrinkles shape control on the metal membrane by means of electrostatic attraction to the electrode was investigated in the paper [20]. The general theory of a fluid impulsive movement under surface impact is given in the paper [21].

\subsection{Electrode Position Height Influence}

To observe the pattern of instability at various distances from the liquid surface up to the electrode, its displacement was being fulfilled height along: 0 - $10 \mathrm{~mm}$ at a pitch of $1 \mathrm{~mm}, 10-54 \mathrm{~mm}$ at a pitch of $2 \mathrm{~mm}$. The funnel diameter was calculated for several frames at a stage of $20 \mathrm{~ms}$ (See Figure 3) at each position. In this case, the frames with the smallest and the largest funnels were not taken into account, the rest ones were averaged. The dependence of the funnel diameter within sunflower oil on the electrode position height is shown in Figure 6.

The diameter determination error is indicated based on the photos: $\pm 5 \%$. The relationship can be approximated by a straight line within the margin of error. There are the frames with a spread of distances from the funnel center to the hydraulic jump line of no more than $20 \%$ up to $10 \mathrm{~mm}$. The scatter becomes wider and dividing of the funnel into parts is observed beginning with the height of $10 \mathrm{~mm}$. Instability is getting a rose-window type with large and mostly irregularly placed cells. A series of instability shots on the transformer oil surface is shown in Figure 7 at a height of $10 \mathrm{~mm}$. The difference from the rose-window classic instability consists in that each cell has a tortuous edge and radially divergent folds. Weaker instabilities of such a type with a larger number of cells are observed up to a height of $54 \mathrm{~mm}$.

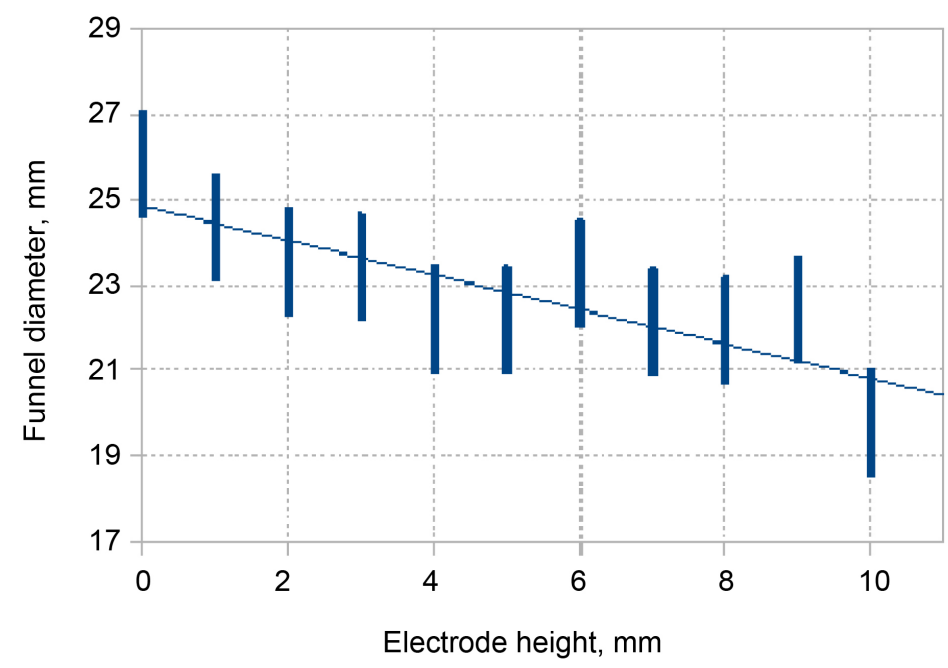

Figure 6. Dependence of funnel diameter on the electrode position height. 


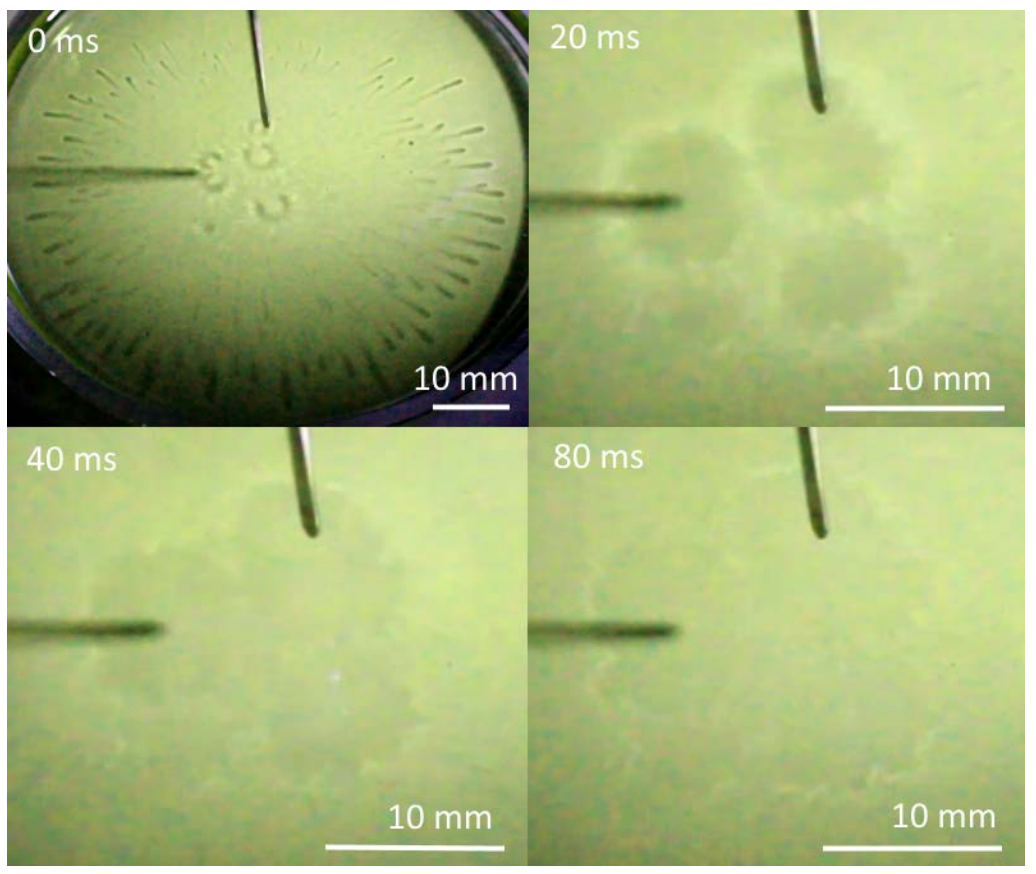

Figure 7. Cell instability on the surface of transformer oil. Electrode position height above the surface is $10 \mathrm{~mm}$.

\subsection{Instability in Thin Liquid Layer}

The series of frames for sunflower oil layer of thickness $1 \mathrm{~mm}$ is presented at Figure 8. The electrode position height is $2 \mathrm{~mm}$. The influence of bottom of the cup leads to certain features of the instability. First, there is an exposure of the bottom. Secondly, the wrinkles around the funnel are denser than in the thick layer of liquid (see Figure 3). Decrease in the depth of the wrinkles leads to their broadening. Thirdly, turbulization of the funnel walls is observed towards the center due to the radial flows of the liquid upon collapse. The effect of liquid layer thickness on the shape of instability is observable for thin layers and practically disappears at the values $>5 \mathrm{~mm}$.

\subsection{Activity of Some Liquids}

The results of activity investigation for a number of dielectric liquids under the action of a corona discharge are presented in Table 1. Herein, $\rho$ is the volumetric resistivity, $\varepsilon$ - dielectric permittivity, $\eta$ - kinematic viscosity. Reference values are given under standard conditions. $\mathrm{D}$ is the average funnel diameter obtained for maximal funnels in a series of at least 520 -ms frames. Accuracy of its determination is about $10 \%$. Bo is the Bond number and $t$ is the estimated value of instability lifetime (up to a distinct view on the frames). The liquids were being located in the Petri dishes with the diameter of $60 \mathrm{~mm}$, the thickness of layers was $5 \mathrm{~mm}$, and the height of the electrode above the surface was $10 \mathrm{~mm}$.

It can be seen from Table 1 that high resistivity dielectrics exhibit activity only. The lifetime of instability is greater with more viscous liquids. The funnel diameter is sufficiently greater with PMS-5 oil which has high conductance at 


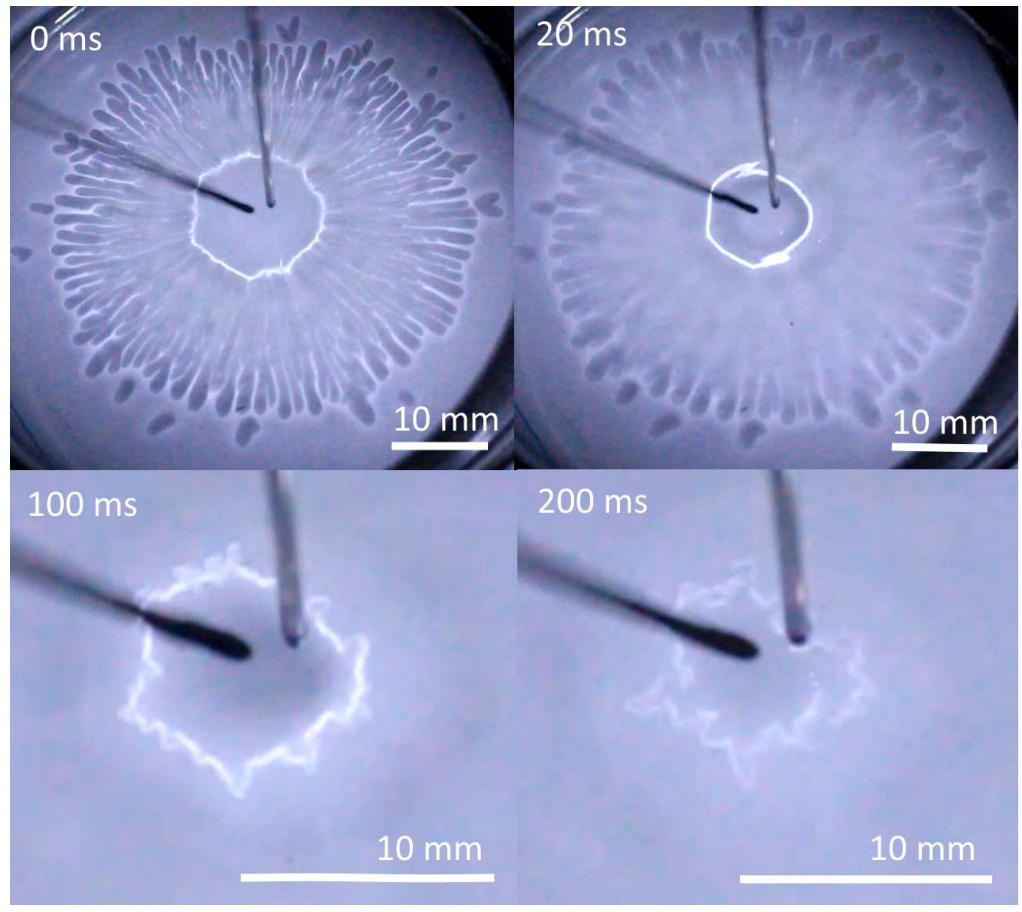

Figure 8. Instability on the surface of a $1 \mathrm{~mm}$-thick sunflower oil layer. Electrode position height above the surface is $2 \mathrm{~mm}$. The pulse voltage is up to about $70 \mathrm{kV}$.

Table 1. Comparison of the liquid dielectrics activity.

\begin{tabular}{|c|c|c|c|c|c|c|}
\hline Name & $\rho, \mathrm{Ohm} \cdot \mathrm{m}$ & $\varepsilon$ & $\eta, \mathrm{mm}^{2} / \mathrm{s}$ & $\mathrm{D}, \mathrm{mm}$ & Bo & $t, s$ \\
\hline distilled water & $10^{3}-10^{4}$ & 80.1 & 1 & - & - & - \\
\hline ethanol & $10^{4}-10^{5}$ & 25 & 2.54 & - & - & - \\
\hline glycerol & $1.5 \times 10^{5}$ & 47 & 870 & - & - & - \\
\hline turpentine & $10^{7}-10^{8}$ & 68 & 1.83 & - & - & - \\
\hline benzene & $10^{10}-10^{12}$ & 2.3 & 0.07 & - & - & - \\
\hline benzine & $10^{10}-10^{12}$ & 2.3 & 0.65 & 3.1 & 2.9 & 0.06 \\
\hline sunflower oil & $10^{9}-10^{12}$ & $3.0-3.2$ & $54-65$ & 3.1 & 2.9 & 0.4 \\
\hline transformer oil & $10^{11}-10^{13}$ & $2.2-2.5$ & $64-75$ & 3.0 & 2.0 & 0.7 \\
\hline silicone oil (PMS-5) & $10^{13}$ & $2.2-2.8$ & 5 & 14.4 & 95.9 & 0.1 \\
\hline $\begin{array}{l}\text { silicone oil } \\
\text { (PMS-100) }\end{array}$ & $10^{13}$ & $2.2-2.8$ & 100 & 3.2 & 4.7 & 1 \\
\hline $\begin{array}{l}\text { silicone oil } \\
\text { (PMS-200) }\end{array}$ & $10^{13}$ & $2.2-2.8$ & 200 & 3.4 & 5.3 & $>2$ \\
\hline
\end{tabular}

low viscosity. Thus PMS-5 instabilities are the most intensive but short-lived. High Bond number shows greatest superiority of gravity forces over capillary forces for these instabilities. Other liquid types have a lower difference in the intensity. The long lifetime is due to high passivity of a viscous liquid. In this case, viscous friction reduces the intensity of disturbance.

A series of frames with PMS-5 and PMS-200 oils are shown in Figure 9. The 


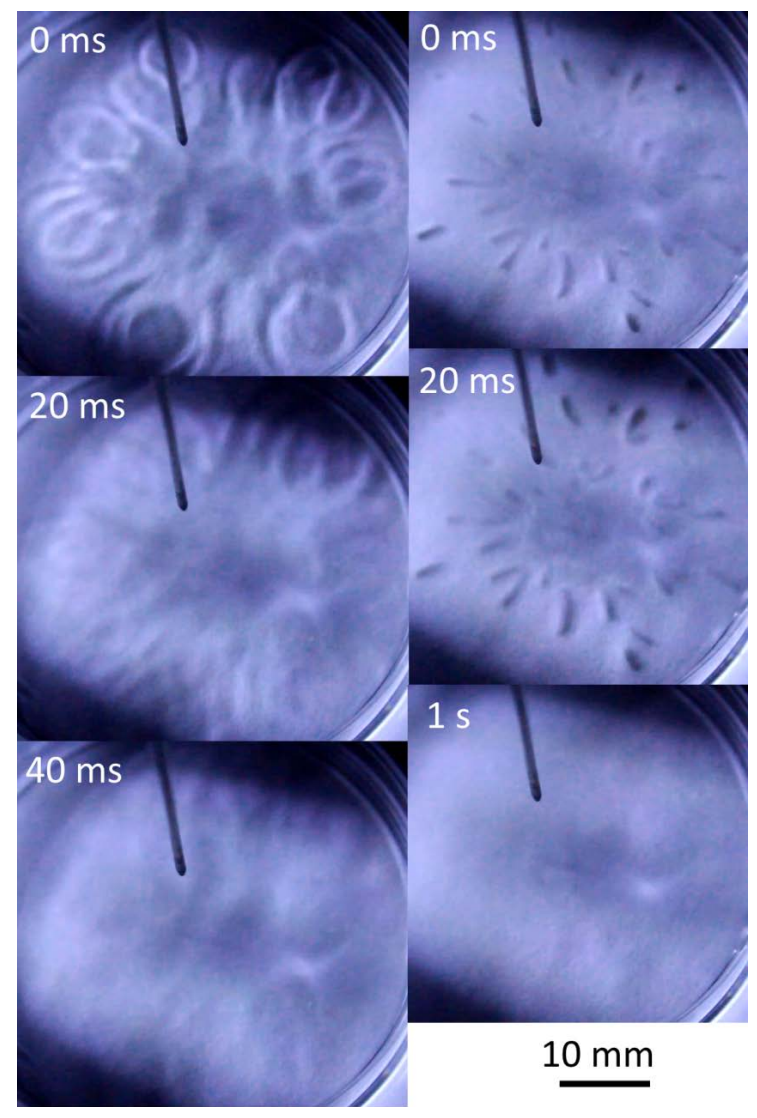

Figure 9. The development of instability on the surfaces of silicone oils. PMS-5 is on the left, PMS-200 is on the right. Electrode position height above the surface is 10 $\mathrm{mm}$. The pulse voltage is up to about $70 \mathrm{kV}$.

size of the funnels with PMS-5 oil is greater than that is with a transformer oil under the same conditions (See Figure 7). They are spreading out much greater in a short time. The longest lifetime was being observed with PMS-200 oil. The shape of instability changes slowly and the cavity is retained on the surface of PMS-200 for a long time.

\section{Conclusions}

High voltage on the corona-producing electrode in combination with short pulse duration causes a special type of instabilities being investigated. Unlike classical rose-window instabilities [8]-[14], turbulization of the cells (funnels) boundaries is observed. There are radially divergent wrinkles in the form of petals around the funnels. There is a single funnel with a sinuous edge surrounded by wrinkles (see Figure 4, Figure 5, and Figure 8) at a low electrode height above the oil surface. The instability of such a type is more like an element of architecture named "oculus".

The funneling and wrinkling around the funnels are explained by the action of electrostatic repulsion forces of charged surface sections from the corona-producing electrode and by stretching due to internal electrostatic forces. The 
instability spreading at a last stage should be mainly by inertia. The widening of the funnel edges occurs turbulently because of the short duration and high intensity of initial push (electric pulse). In such a case, the profile of a hydraulic jump becomes tortuous. In this case, tensile mechanical stresses act against the surface tension forces and are maximum ones in the surface charge density maximum region, i.e. near the funnel.

Inactivity of liquid dielectrics with a relatively low resistivity acknowledges the electrostatic nature of forces acting on the surface. It was demonstrated in the paper [12] that the size of the funnel also increases with oil temperature increase. Such a result is explained by oil viscosity reduction, which prevents the growth of instability. The greatest intensity of instabilities is observed in the present paper for liquid dielectrics with high specific resistivity and low viscosity. Whereas, the lifetime of instabilities is greater with viscous liquids.

\section{References}

[1] Sticher, J. and Thomas, D. (1939) Effect of Corona Discharge on Liquid Dielectrics. Transactions of the American Institute of Electrical Engineers, 58, 12. https://doi.org/10.1109/T-AIEE.1939.5057888

[2] Aleksandrov, A., Bichkov, V., et al. (2011) Elektrogydrodynamicheskie osobennosti vzaimodeistvia koronnogo razrjada s poverhnost'u jidkosti. MSU Vestnik. Series 3 , 4,67 .

[3] Takeuchi, N. and Takubo, K. (2015) Mass Transfer Enhancement of Reactive Species by Gas- and Liquid-Phase Flow Induced by Corona Discharge Generated above Water. International Journal of Plasma Environmental Science \& Technology, 9, 1.

[4] Mahmoudi, S., et al. (2011) Spreading of a Dielectric Droplet through an Interfacial Electric Pressure. Proceedings of the Royal Society, 467, 3257-3271. https://doi.org/10.1098/rspa.2011.0220

[5] Mahmoudi, S., et al. (2013) On the Corona Discharge Spreading of Dielectric Liquid Films. Journal of Electrostatics, 71, 496-498. https://doi.org/10.1016/j.elstat.2012.12.038

[6] Chang, J., Urashima, K., et al. (1997) Electrohydrodynamic Pressure Drop in a Silent and Superimposed Barrier Discharge. IEEE Annual Report Conference on Electrical Insulation and Dielectric Phenomena. Minneapolis, 19-22 October 1997, 668-671.

[7] Fedirchyk, I., Nedybaliuk, O., et al. (2015) Influence of Plasma on Surface Tension of Hydrocarbons. Problems of Atomic Science and Technology. No. 1. Series: Plasma Physics, No. 21, 239-242.

[8] Vega, F. and Pérez, A. (2003) Corona-Induced Electrohydrodynamic Instabilities in Low Conducting Liquids. Experiments in Fluids, 34, 726-735. https://doi.org/10.1007/s00348-003-0616-y

[9] Vega, F. and Garc1'a, F. (2006) Pattern Imaging of Primary and Secondary Electrohydrodynamic Instabilities. Journal of Fluid Mechanics, 549, 61-69. https://doi.org/10.1017/S0022112005007706

[10] Chicón, R. and Pérez, A. (2006) Instability of an Interface between Air and a Low Conducting Liquid Subjected to Charge Injection. Physics of Fluids, 18, 104-108. https://doi.org/10.1063/1.2363219

[11] Vega, F. and Garci'a, F. (2008) Geometric Properties of the Patterns Observed in 
Low Conducting Liquids under Corona Discharge. Journal of Electrostatics, 66, 178-183. https://doi.org/10.1016/j.elstat.2007.12.001

[12] Xie, G., Yang, Y., et al. (2013) AC Pulse Dielectric Barrier Corona Discharge over Oil Surfaces: Effect of Oil Temperature. IEEE Transactions on Plasma Science, 41, 481-484. https://doi.org/10.1109/TPS.2012.2230341

[13] Saranin, V., et al. (2014) Neustoichivost' ravnovesia poverhnosti zhidkogo dielectrika I obrazovanie reguljarnyh jacheistyh structur v pole koronnogo razrjada. JETF, 2, 398-404.

[14] Guo, Z., et al. (2016) Rose-Window Instability of Oil Surfaces Exposed In Corona Discharge.

http://www.yau-awards.science/wp-content/uploads/2016/11/Rose-Window-Instabi lity-of-Oil-Surfaces-Exposed-In-Corona-Discharge-论文正文-20160820.pdf https://doi.org/10.1351/pac198557091353

[15] Goldman, M., et al. (1985) The Corona Discharge, Its Properties and Specific Uses. Pure and Applied Chemistry, 57, 1353-1362.

[16] Rybka, D., Andronikov, I., et al. (2013) Corona Discharge in Atmospheric Pressure Air under a Modulated Voltage Pulse of $10 \mathrm{~ms}$. Atmospheric and Oceanic Optics, 26, 449-453. https://doi.org/10.1134/S1024856013050138

[17] Brutin, D. (2003) Drop Impingement on a Deep Liquid Surface: Study of a Crater's Sinking Dynamics. C. R. Mecanique, 331, 61-67. https://doi.org/10.1016/S1631-0721(02)00014-1

[18] Brown, C., et al. (2010) Amplitude Scaling of a Static Wrinkle at an Oil-Air Interface Created by Dielectrophoresis Forces. Applied Physics Letters, 97, Article ID: 242904.

[19] McHale, G., Brown, C., et al. (2012) Developing Interface Localized Liquid Dielectrophoresis for Optical Applications. Proc. SPIE, 8557, Article ID: 855703. https://doi.org/10.1117/12.2001442

[20] Wu, X., et al. (2007) Wrinkling of a Charged Elastic Film on a Viscous Layer. Meccanica, 42, 273-282. https://doi.org/10.1007/s11012-007-9054-X

[21] Bachelor, D. (1973) Vvedenie v dinamiky jidkosti. Mir, Moscow, 580. 